\title{
GPS Height and Gravity Variations Due to Ocean Tidal Loading Around Taiwan
}

\author{
Ta-Kang Yeh $\cdot$ Cheinway Hwang • Guochang Xu
}

Published online: 14 January 2009

(C) Springer Science+Business Media B.V. 2009

\section{Erratum to: Surv Geophys (2008) 29:37-50 \\ DOI: 10.1007/s10712-008-9041-3}

In the above-mentioned paper, which was published in Volume 29 , No. 1 on pp. 37-50, a typing mistake of the second author's last name was not corrected. The name of the second author is Cheinway Hwang (not Cheinway Huang).

We sincerely regret this error and would like to make sure the correct information is published to increase the scientific value of the paper.

The online version of the original article can be found under doi:10.1007/s10712-008-9041-3.

T.-K. Yeh $(\bowtie)$

Institute of Geomatics and Disaster Prevention Technology, Ching Yun University, No. 229, Jiansing Rd., Jhongli 320, Taiwan, ROC

e-mail: bigsteel@cyu.edu.tw

C. Hwang

Department of Civil Engineering, National Chiao Tung University, No. 1001,

Tahsueh Rd., Hsinchu 300, Taiwan, ROC

G. $\mathrm{Xu}$

Department of Geodesy and Remote Sensing, GeoForschungsZentrum Potsdam, Telegrafenberg A17, 14473 Potsdam, Germany 